\title{
Does Context Matter?
}

Differences in the Use of Congregate Care by Black, White, and Hispanic Youth

\author{
Fred Wulczyn ${ }^{1}$ \\ Scott Huhr ${ }^{1}$ \\ Kristen Hislop ${ }^{1}$ \\ Florie Schmits ${ }^{1}$ \\ Amy Dworsky ${ }^{2}$ \\ John Halloran ${ }^{3}$
}

${ }^{1}$ Center for State Child Welfare Data, Chapin Hall, University of Chicago

${ }^{2}$ Chapin Hall, University of Chicago

${ }^{3}$ School of Social Work, Lewis University 


\begin{abstract}
*
In the paper, we examine the relationship between county context and the use of congregate care by White, Black, and Hispanic youth, aged between 10 and 17 . We measure the use of congregate care as the probability a young person will be placed in congregate care during an out-of-home care spell. We define county context in three ways: urbanicity, social disadvantage, and the supply effect on demand. We also include whether states mandate the use of an assessment to regulate entry into congregate care. Our primary interest is organized around differences in county context, the rate of congregate care utilization, and the connection between context and disparity. We find that, regardless of race, congregate care placement rates tend to be higher in counties where supply affects demand. However, in those counties, the Black/White disparity tends to be lower and the Hispanic/White disparity tends to be higher. The association between a mandatory assessment policy and congregate care placement is in the expected direction. After describing the study limitations, we discuss implications for future research and policy.
\end{abstract}

Keywords: congregate care, disparities, multilevel models, supply-induced demand, state policy

\footnotetext{
* The research reported was approved by the University of Chicago IRB. Consent was waived because the research presents no more than minimal risk to subjects, a waiver of informed consent will not adversely affect the rights and welfare of subjects, and it would be impracticable to carry out the research without a waiver. Research presents no more than minimal risk to subject's privacy.
} 


\section{Does Context Matter?:}

\section{Differences in Congregate Care Use by Black, White and Hispanic Youth}

In the paper, we examine the relationship between county context and the use of congregate care by White, Black, and Hispanic youth, aged between 10 and 17. When young people are unable to live safely at home with their families, states typically place them in out-of-home care. Out-of-home care placement options exist along a continuum, ranging from the home of relatives to non-relative foster homes to congregate care settings, a category that includes shelters, group homes, and residential treatment facilities. These congregate care settings can serve as few as seven children or as many as several hundred.

We measure the use of congregate care as the probability a young person will be placed in congregate care during an out-of-home care spell. We define county context in three ways: urbanicity, social disadvantage, and the supply effect on demand. We know that congregate care use, as defined above, varies within states at the county-level (Wulczyn et al., 2015). Variation may be partially explained by urban/suburban/rural differences in access to congregate care. Additionally, we expect that utilization rates will be higher in counties with greater levels of social disadvantage. Although a child welfare system can be described in various ways (Wulczyn et al., 2010), we focus in on whether there is evidence, at the county-level, that the probability of placement in congregate care is tied to the supply of beds.

In addition to the county-level analysis, we situate the county context within states to capture a final element of context: state child welfare policy. In the United States, the federal government sets forth broad policy guidance in the child welfare domain. So long as state public child welfare agencies operate within those guidelines, states are free to adopt policies and practices suited to local priorities. In keeping with that discretion, states have, over the years, 
applied a range of policy options meant to influence the use of congregate care (Wulczyn \& Huang, 2018). One option mandated by some states is the use of assessments to determine whether a young person is best served in congregate care despite a general preference for familybased care. In other states, the law is silent about the use of assessments, although use of assessments may be a local practice. The final question we address is whether the mandated use of assessments correlates with differences in the use of congregate care, as one might expect.

The motivation for the study is two-fold. First, public policy in the United States favors the placement of children with families whenever possible, a preference that is rooted in the uncertainties about the net effects of congregate care on child wellbeing (Dozier et al., 2014). Given those uncertainties, if Black and/or Hispanic children are more likely to be placed in congregate care, it is appropriate to ask whether the tendency to use congregate care might add somehow to the burdens already facing Black and Hispanic youth. That said, differential use of congregate care by Black, Hispanic, and White youth is an area that has received hardly any empirical attention.

Second, we want to elevate the importance of context when it comes to how we study disparity within the child welfare system. Considerable research has been done exploring whether disparities in the child welfare system are present and the cumulative evidence is persuasive. Black and Hispanic children do have different experiences within the child welfare system, regardless of whether those differences are measured in terms of reporting rates, substantiation rates, placement rates, or permanency rates (Fluke et al., 2011). Nevertheless, much more attention should be paid to comparative research that explores levels of disparity as observed in places differentiated from one another in meaningful ways, whether that meaning is derived from theory, policy, practice, or some combination of all three. 
In the case of congregate care, we ask whether the likelihood of congregate placement is higher for Black and Hispanic youth as compared to White youth. We then ask whether the level of disparity is higher (or lower) in counties where the level of social disadvantage is greater, where there is evidence of a supply effect on demand, and where there are policies in place that call for an assessment of need prior to congregate care placement. The answers to these questions are relevant, we contend, because, if found, variation in the level of disparity should shape the way we build systems that are equitable in their treatment of children, regardless of race and/or ethnicity.

\section{Theoretical Orientation}

To organize our study of congregate care as a placement option, we bring together two theoretical perspectives: supply-induced demand and ecological similarity. We start with the notion of supply-induced demand as a system characteristic. Attributed to Milton Roemer (1961), supply-induced demand refers to the idea that built beds tend to be used. To test whether the supply of congregate care beds affects the use of congregate care, we apply lessons from population ecology that link the changes in population size to the carrying capacity of the environment. In the case of congregate care, the population is the number of children in congregate care settings, which changes when children are admitted and discharged from those settings. The carrying capacity is the number of congregate care beds. The dynamics of the system are organized around forces that require some number of filled beds in order to operate the congregate care system (Wulczyn \& Halloran, 2017). These forces produce admission and discharge processes which adapt to the carrying capacity and the size of the congregate care population. We contend that admissions to congregate care will tend to be higher where our 
measure of admission and discharge processes in the face of resource constraints shows a builtbed-filled-bed dynamic. We refer to this dynamic as supply induced demand.

The second perspective draws on the theory of ecological similarity (Sampson \& Bean, 2006). As a theoretical perspective, ecological similarity grew out of the observations that social disorganization affected rates of juvenile delinquency. Updated versions of the theory emphasize the role of social context and collective efficacy as the mechanisms that transmit the influence of a community on the people who live there including children. Methodologically, the theory stresses the extent to which similarities in ecological context are used to understand individuallevel phenomena.

To observe the influence of context on outcomes, it is important to apply robust statistical models. The goal is to compare outcomes for children who come from ecologically similar areas. In our study, ecological similarity is defined by urbanicity, social disadvantage, the supply effect on demand at the county level, and assessment policy at the state level. Although finding White children raised under conditions similar to those affecting Black and Hispanic children is not always easy because of residential and economic segregation, comparisons within ecologically similar contexts should yield theoretical insights with practical utility (Wulczyn et al., 2013).

We bring these two theoretical perspectives together as follows. We start with the contention that differences in the likelihood of congregate care placement are a function of context. Specifically, baseline rates of congregate care placement will vary by urbanicity, the level of social disadvantage at the county level, the supply effect on utilization measured at the countylevel, and the state policy context. Regarding disparity, we are interested in the association between county context, state policy context, and the probability that a White, Black, or Hispanic child will be placed in congregate care. Finally, given any observed differences, we want to 
understand how the level of disparity shifts from one context to another. Rather than assume that disparity rates vary tightly around a single mean for all counties, we ask whether the counties with elevated rates of disparity share other characteristics.

\section{Research Questions and Hypotheses}

Although we are interested ultimately in why disparities arise, for this study, our attention is drawn first to Black, White, and Hispanic differences in the utilization of congregate care. As noted, we measure congregate care utilization as the probability that a young person will be placed in congregate care at any point during their time in foster care. Although whether one sees this as a broad or narrow definition of utilization is a matter of perspective; we freely acknowledge there are other ways to explore congregate care utilization such as length of stay, setting type (group homes vs. shelters vs. residential treatment facilities), and timing (initial placements vs subsequent placements). That said, our analysis is exploratory and does not exhaust all the possible ways one might zero in on how much congregate is being used and why.

Our primary interest is organized around differences in county context, the rate of congregate care utilization, and the connection between context and disparity. Our study addresses these hypotheses. The relationship between age, gender, and congregate care placement is easy to anticipate. We expect males and older adolescents to have the highest rates of congregate care placement. Expectations vis-á-vis urbanicity and social disadvantage are less clear-cut given the lack of comparative research in the field. Given the higher rates of placement in urban areas and places where social disadvantage is more commonplace, it is easy to assume that congregate care utilization will follow a similar pattern.

The hypotheses most central to the study concern supply induced demand and policies that pertain to the use of assessments. Starting with the latter, policies that mandate the use of an 
assessment are intended to limit access to congregate care to those young people with a clinical profile that aligns with the treatment provided in congregate care settings so we expect lower rates of congregate care placement in counties located in states with a policy that mandates assessment. With respect to the former, supply induced demand is expected to raise the level of congregate care utilization for reasons inherent to the notion of supply induce demand: a built bed will tend to be filled.

How will the use of assessments as a matter of policy and supply induced demand affect observed disparities? The answer ties back to why ecological similarity is important. Theory suggests that when we compare the experience of White children relative to those of children of other races and ethnicities, their experiences will be more similar when context is taken into account. We expect higher rates of congregate care placement in counties where there is evidence of supply induced demand. Consequently, if White children tend to live in places where there is no supply effect on demand but Black and/or Hispanic children tend to live where the supply effect on demand is strong, then an unweighted measure of disparity will reflect where children live rather than a propensity to place Black and/or Hispanic children that is distinctive. To avoid that problem, measures of disparity should examine what happens when Black and Hispanic children are compared with White children who live in a similar context. In the case of congregate care, we expect disparity to attenuate because White, Black, and Hispanic youth are all more likely to be placed in congregate care when they live in places where supply induces demand. This is not to suggest in any way that disparity is somehow unimportant. On the contrary, by isolating places where disparity tends to be greater, we hope to prompt a new generation of questions that probe what else is distinctive about the places where disparities persist at levels that are above average. 


\section{Data and Methods}

\section{Sample}

For the analysis presented here, we examine admissions into foster care of children placed for the first time between 2010 and 2015 by state and county. Only youth age 10 through 17 are included in the analysis because placements of younger children in congregate care, although they do happen, are relatively rare. We track older admission cohorts (i.e., 2010 - 2015) to minimize the effects of right censoring. The data source is the Multistate Foster Care Data Archive (Wulczyn et al., 2015). A total of 17 states are included in the analysis and the number of youth equals 138,862 .

\section{Dependent Variable}

The dependent variable in the model is the probability of placement in congregate care at any point in a given child's first placement spell. There are three possible placement types. As mentioned, congregate care is non-family-based care and includes group homes, along with shelters and other various residential settings as defined by the states. Foster care and kinship care are family-based placement options and are the preferred choice from a policy and practice perspective.

\section{Independent Variables}

The independent variables are grouped into three clusters: child-level variables that describe the children placed, county-level variables that describe the county where the child was living at the time of placement, and one state-level variable that indicates whether the state mandates the use of an assessment as a way to regulate entry in congregate care. Child-level variables, in addition to age at entry, include race and gender. Age refers to the young person's age at time of their initial placement. The study focuses on Black, Hispanic, and White children. That said, we 
acknowledge that children placed in foster care come from backgrounds that are more diverse than those included here. County-level variables include urbanicity, an index of social disadvantage, and a measure of the supply effect on demand. Urbanicity, which captures the urban character of the county, uses the classification scheme developed by the National Center for Health Statistics (Ingram \& Franco, 2014). We reduced the six categories to three: large urban core counties, other large urban counties, and non-urban counties. For socioeconomic disadvantage, we categorize each county relative to their state on four indicators based on the 2010 U.S. Census: poverty rate, percentage of people with less than a high school education, unemployment rate, and percentage of homes with a single head of household. For example, counties with a higher rate of poverty than the state poverty rate are were assigned a value of one; counties with a lower poverty rate were assigned a value of zero. The results are then summed across the four indicators to create an index ranging from 0 to 4 . A county with a score of 0 would have a low rate of socioeconomic disadvantage because it is below the state average on each of the indicators whereas a county with a score of 4 would have a high rate of disadvantage (Wulczyn et al., 2013).

Regarding whether demand is supply induced, we use Convergent Cross-Mapping (CCM). CCM, developed by population ecologists, tests the idea that a system produces time series data tied to the structure of the system (Sugihara et al., 2012). In our study, we hypothesize that the structure of the system is reflective of resource dependencies that systematically impact the number of admissions to and discharges from congregate care. To test for the resource constraint, we assembled the number of admissions to and discharges from congregate care each week for each county in the data set for ten years. For each county time-series, we computed the CCM coefficient. We then divided the counties into those where the time series allowed the 
computation of a coefficient and those counties where no CCM coefficient could be determined. Generally, though not exclusively, counties that were associated with no calculable CCM coefficient are smaller counties where the number of admissions and discharges is small and the time series data reveal little to no apparent structure. From this grouping of counties, we created a dummy variable corresponding to counties with a supply signal—-those with a coefficient further away from zero - and counties without a signal— those with a coefficient of zero or near zero. We expect the likelihood of placement in congregate care to be higher in counties with a supply signal relative to counties with no detectable signal, all else being equal.

To gather policy data, we read each state's policy and regulatory guidance. The state policy variable of interest is whether the state had a provision in statute or regulation that mandates the use of a standardized assessment for determining whether a placement in congregate care is appropriate. We found that some states referenced a general requirement whereas other states referenced a specific assessment tool. Both groups of states were coded as having specific assessment language. In the event the policies in place were unclear, we also conducted interviews with state policy officials to reach clarity.

\section{Statistical Analysis}

For the analysis, we rely on logistic regression to answer the question: how likely is it that a youth between the ages of 10 and 17, having been admitted to foster care between 2010 and 2015, will be placed in congregate care. To account for the nested structure of the data (i.e., youth within counties and counties within states), we use hierarchical models with county and state random intercepts. We follow a stepwise approach to the analysis that tracks our theoretical orientation. The first phase of the analysis uses only the child-level variables. We expect to find that White youth have different congregate care placement rates than either Black or Hispanic 
youth, even after controlling for other child-level factors. As a second step, we add county attributes to the model to test whether observed disparities are sensitive to county context. Per theory, we expect our analysis will show that congregate placements are influenced by context, with higher placement rates observed in counties where we observe a supply effect on demand and where social disadvantage is greater.

The third phase of the analysis adds state policy to the model. Among other things, the county random effects account for unobserved differences between the counties. The random effects also account for differences in the size of the counties so that large counties do not unduly influence the results. If large counties have unusually high congregate care placement rates and/or large populations of Black or Hispanic youth, then the random effects model adjusts for those imbalances. The state random effects account for unobserved between-state differences. With the addition of the county random and state random effects we expect some adjustment to the residual direct effect of race on congregate care placement.

\section{Findings}

\section{Descriptive Statistics}

We start with a simple descriptive summary of the youth in the sample. Table 1 shows the number of youth in the sample by race and ethnicity, gender and age. Overall, in this collection of states, 44.6 percent of the 10- to 17-year olds entering care between 2010 and 2015 were placed in a congregate care setting at some point during their first foster care spell. As expected, the likelihood of placement in congregate care is greater for Black youth (50\%) than White youth (45\%). However, Hispanic youth (39.6\%) are much less likely to be placed in congregate care than either White or Black youth. The unadjusted ratio of the Black/White odds is 1.25. The unadjusted ratio of the Hispanic/White odds is .81 . Table 1 also shows the likelihood of 
placement in congregate care by gender and age. Males are more likely to be placed in congregate care than females. The likelihood of congregate care placement increases as the age of entry increases, from $24 \%$ of youth who entered at age 10 to $56.6 \%$ of youth who entered at ages 16 and 17.

Table 1: Congregate Placement During First Placement Spells by Race/Ethnicity, Gender, and Age at Admission: 2010 - 2016

\begin{tabular}{|c|c|c|c|c|c|c|}
\hline \multirow[b]{2}{*}{ Child Characteristics } & \multicolumn{3}{|c|}{$\begin{array}{c}\text { Number } \\
\text { Any Congregate Care }\end{array}$} & \multicolumn{3}{|c|}{$\begin{array}{c}\text { Percent } \\
\text { Any Congregate Care }\end{array}$} \\
\hline & No & Yes & Total & No & Yes & Total \\
\hline \multicolumn{7}{|l|}{ Race/ethnicity } \\
\hline White & 32,643 & 26,184 & 58,827 & $55.5 \%$ & $44.5 \%$ & $100.0 \%$ \\
\hline Black & 19,304 & 19,324 & 38,628 & $60.4 \%$ & $39.6 \%$ & $100.0 \%$ \\
\hline Hispanic & 25,020 & 16,387 & 41,407 & $50.0 \%$ & $50.0 \%$ & $100.0 \%$ \\
\hline \multicolumn{7}{|l|}{ Gender } \\
\hline Female & 43,593 & 30,444 & 74,037 & $58.9 \%$ & $41.1 \%$ & $100.0 \%$ \\
\hline Male & 33,374 & 31,451 & 64,825 & $51.5 \%$ & $48.5 \%$ & $100.0 \%$ \\
\hline \multicolumn{7}{|l|}{ Age at admission } \\
\hline 10 & 13,413 & 4,161 & 17,574 & $76.3 \%$ & $23.7 \%$ & $100.0 \%$ \\
\hline 11 & 11,765 & 4,678 & 16,443 & $71.6 \%$ & $28.4 \%$ & $100.0 \%$ \\
\hline $12 \& 13$ & 20,623 & 14,379 & 35,002 & $58.9 \%$ & $41.1 \%$ & $100.0 \%$ \\
\hline $14 \& 15$ & 17,918 & 21,427 & 39,345 & $45.5 \%$ & $54.5 \%$ & $100.0 \%$ \\
\hline $16 \& 17$ & 13,248 & 17,250 & 30,498 & $43.4 \%$ & $56.6 \%$ & $100.0 \%$ \\
\hline Total Children & 76,967 & 61,895 & 138,862 & $55.4 \%$ & $44.6 \%$ & $100.0 \%$ \\
\hline
\end{tabular}

Table 2 shows how the chances a young person will be placed in congregate care vary by county characteristics and state policy context. Other large urban counties have the highest congregate care placement rates followed by urban and non-urban counties. In counties where a supply effect on demand was detected, the likelihood of congregate care placement into is 46.7 percent; in counties where a supply effect on demand could not be detected, the likelihood of congregate care placement is 38.0 percent. Youth from the least disadvantaged counties have a higher congregate care placement rate $(54 \%)$ than youth from more disadvantaged counties $(36 \%$ to $50 \%$ ). Finally, the congregate care placement rate is lower in states that mandate the use of an assessment (40\%) than in states where the use of an assessment is not mandated (47\%). 
Table 2: Any Placement in Congregate Care by County and State Policy Context: 2010 - 2015

\begin{tabular}{|c|c|c|c|c|c|c|}
\hline \multirow[b]{2}{*}{ County Characteristics } & \multicolumn{3}{|c|}{$\begin{array}{c}\text { Number } \\
\text { Any Congregate Care }\end{array}$} & \multicolumn{3}{|c|}{$\begin{array}{c}\text { Percent } \\
\text { Any Congregate Care }\end{array}$} \\
\hline & No & Yes & Total & No & Yes & Total \\
\hline \multicolumn{7}{|l|}{ Urbanicity } \\
\hline Urban core & 30,223 & 22,953 & 53,176 & $56.8 \%$ & $43.2 \%$ & $100.0 \%$ \\
\hline Other urban areas & 27,848 & 25,937 & 53,785 & $51.8 \%$ & $48.2 \%$ & $100.0 \%$ \\
\hline Non-urban areas & 18,896 & 13,005 & 31,901 & $59.2 \%$ & $40.8 \%$ & $100.0 \%$ \\
\hline \multicolumn{7}{|l|}{ Social Disadvantage } \\
\hline Lowest & 15,909 & 18,793 & 34,702 & $45.8 \%$ & $54.2 \%$ & $100.0 \%$ \\
\hline 1 & 8,111 & 8,147 & 16,258 & $49.9 \%$ & $50.1 \%$ & $100.0 \%$ \\
\hline 2 & 12,435 & 8,985 & 21,420 & $58.1 \%$ & $41.9 \%$ & $100.0 \%$ \\
\hline 3 & 19,536 & 11,164 & 30,700 & $63.6 \%$ & $36.4 \%$ & $100.0 \%$ \\
\hline Highest & 20,976 & 14,806 & 35,782 & $58.6 \%$ & $41.4 \%$ & $100.0 \%$ \\
\hline \multicolumn{7}{|l|}{ Supply Effect } \\
\hline No signal & 20,736 & 12,691 & 33,427 & $62.0 \%$ & $38.0 \%$ & $100.0 \%$ \\
\hline Signal & 56,231 & 49,204 & 105,435 & $53.3 \%$ & $46.7 \%$ & $100.0 \%$ \\
\hline \multicolumn{7}{|l|}{ Assessment Policy } \\
\hline No & 44,865 & 40,427 & 85,292 & $52.6 \%$ & $47.4 \%$ & $100.0 \%$ \\
\hline Yes & 32,102 & 21,468 & 53,570 & $59.9 \%$ & $40.1 \%$ & $100.0 \%$ \\
\hline Total Children & 76,967 & 61,895 & 138,862 & $55.4 \%$ & $44.6 \%$ & $100.0 \%$ \\
\hline
\end{tabular}

Table 3 shows the distribution of entries into care by county and state policy context and race/ethnicity. Not surprisingly, youth entering care in urban core counties are predominantly Black and Hispanic (35.2\% and 43.1\%, respectively). By contrast, in other large urban and nonurban counties, the plurality of youth entering care are White ( $49.9 \%$ and $72.0 \%$, respectively). In counties with a low-level of social disadvantage, the largest group of youth entering care are White. As the level of social disadvantage increases, the proportion of youth entering care who are White shrinks while the proportion of youth entering care who are Black and Hispanic grows. In the most disadvantaged counties, 39.2 percent of the youth entering care are Black, 32.5 percent are Hispanic and 28.2 percent are White.

County context as defined by the presence of a supply signal is also associated with racial and ethnic differences in foster care entries. In counties where no supply signal was detected (i.e., no apparent effect of supply on demand), the overwhelming majority of youth entering care 
are White $(70 \%)$. In part, this reflects the fact that White youth tend to come from non-urban counties and the counties with no supply signal tend to be non-urban. By way of contrast, congregate care entries are about equally divided among Black, Hispanic and White youth in counties where there is a supply signal. Lastly, about 50 percent of the youth entering care in states that mandate the use of an assessment are White, 29 percent are Black and 21 percent are Hispanic.

Table 3: Foster Care Admissions by County and State Policy Context and Race/Ethnicity: 2010-2015

\begin{tabular}{lcccccccc}
\hline & \multicolumn{9}{c}{ Number } & \multicolumn{4}{c}{ Percent } \\
& Black & Hispanic & White & Total & Black & Hispanic & White & Total \\
\hline Urbanicity & & & & & & & & \\
$\quad$ Urban core & 18,712 & 22,909 & 11,555 & 53,176 & $35.2 \%$ & $43.1 \%$ & $21.7 \%$ & $100.0 \%$ \\
$\quad$ Other urban areas & 16,956 & 15,780 & 32,648 & 65,384 & $25.9 \%$ & $24.1 \%$ & $49.9 \%$ & $100.0 \%$ \\
$\quad$ Non-urban areas & 2,960 & 2,718 & 14,624 & 20,302 & $14.6 \%$ & $13.4 \%$ & $72.0 \%$ & $100.0 \%$ \\
Social Disadvantage & & & & & & & & \\
$\quad$ - Low & 7,403 & 10,913 & 16,386 & 34,702 & $21.3 \%$ & $31.4 \%$ & $47.2 \%$ & $100.0 \%$ \\
$\quad$ 1 & 3,904 & 2,407 & 9,947 & 16,258 & $24.0 \%$ & $14.8 \%$ & $61.2 \%$ & $100.0 \%$ \\
2 & 5,740 & 4,976 & 10,704 & 21,420 & $26.8 \%$ & $23.2 \%$ & $50.0 \%$ & $100.0 \%$ \\
3 & 7,540 & 11,465 & 11,695 & 30,700 & $24.6 \%$ & $37.3 \%$ & $38.1 \%$ & $100.0 \%$ \\
$\quad$ - High & 14,041 & 11,646 & 10,095 & 35,782 & $39.2 \%$ & $32.5 \%$ & $28.2 \%$ & $100.0 \%$ \\
Supply effect & & & & & & & & \\
$\quad$ No signal & 5,756 & 4,328 & 23,343 & 33,427 & $17.2 \%$ & $12.9 \%$ & $69.8 \%$ & $100.0 \%$ \\
$\quad$ Signal & 32,872 & 37,079 & 35,484 & 105,435 & $31.2 \%$ & $35.2 \%$ & $33.7 \%$ & $100.0 \%$ \\
Assessment policy & & & & & & & & \\
$\quad$ No & 23,201 & 30,274 & 31,817 & 85,292 & $27.2 \%$ & $35.5 \%$ & $37.3 \%$ & $100.0 \%$ \\
$\quad$ Yes & 15,427 & 11,133 & 27,010 & 53,570 & $28.8 \%$ & $20.8 \%$ & $50.4 \%$ & $100.0 \%$ \\
Total & 38,628 & 41,407 & 58,827 & 138,862 & $27.8 \%$ & $29.8 \%$ & $42.4 \%$ & $100.0 \%$ \\
\hline
\end{tabular}

\section{Multivariate analysis}

The results in Tables 1 through 3 suggest that congregate care placement rates along with the race/ethnicity of the youth entering care are correlated with attributes of place. Black youth, for example, are more likely to enter care in places where the congregate care placement rate tends to be lower (e.g., urban areas and areas with higher levels of social disadvantage). Going 
forward, the question is whether the differential exposure to context influences our understanding of Black, Hispanic, and White differences in the use of congregate care.

To test whether the county context and state policy are correlated with disparities in rates of congregate care placement, we estimate a series of increasingly complex multivariate models, starting with intercept only logistic regression models and finishing with mixed effects regression models that include youth characteristics (i.e., race, gender, and age) and the characteristics of the counties where youth were living when they entered care. As the models increase in complexity, we expect the Black/White and Hispanic/White gaps to shift as a reflection of their differential exposure to county context and state policy.

We start by estimating three simple logistic regression models (see Table 4) intended to establish the Black/White and the Hispanic/White gaps. Model 1in Table 4 is an unconditional intercept only model that replicates the overall probability of congregate care placement $(46.6 \%$, see Table 1). Model 2 in Table 4 reproduces the likelihood of congregate care placement for White, Black, and Hispanic youth. Model 3 in Table 4 includes race/ethnicity, gender, and age as well as an intercept with Whites serving as the reference group. As such, the coefficients (the log of the odds ratio) for Black and Hispanic youth are a measure of relative risk and the odds ratios are exponentiated coefficients for Black and Hispanic youths after adjusting for other covariates in the model. For example, the parameter estimates for Model 3 show that after adjusting for gender and age, the Black/White Disparity is 1.22 and the Hispanic/White disparity is. 84 .

The Model 3 intercept represents the relative risk for youth belonging to the omitted categories: White females who entered care at age 10 . Twenty percent of those youth enter congregate care. For a Black female who entered care at age 10, the odds of being placed in congregate care are 1.22 times higher. Consistent with the figures shown in Table 1, males are 
more likely to enter congregate care than females (odds ratio of 1.46). The positive correlation between age at entry and congregate care placement shown in Table 1 is also replicated. Black males who entered care at age 16 or 17 have the highest relative risk of congregate care placement: $\operatorname{logit}=1.37+0.2+1.46+.38=.67$ and probability $=\exp (0.67) /(1+\exp (0.67))$ $=.66$. This is equivalent to a probability of 66 percent.

Table 4: Logistic Regression Model - Child-level Effects on Placement in Congregate Care

\begin{tabular}{|c|c|c|c|c|}
\hline Effect & Estimate & Std Err & Prob. $\mathrm{t}$ & $\begin{array}{c}\text { (Prob.)/ } \\
\text { Odds Ratio }\end{array}$ \\
\hline $\begin{array}{l}\text { Model } 1 \\
\quad \text { Intercept }\end{array}$ & -0.22 & 0.01 & 0.001 & $(44.6 \%)$ \\
\hline Model 2 & & & & \\
\hline $\begin{array}{l}\text { Race/ethnicity } \\
\text { White } \\
\text { Black } \\
\text { Hispanic }\end{array}$ & $\begin{array}{c}-0.22 \\
0.00 \\
-0.42\end{array}$ & $\begin{array}{l}0.01 \\
0.01 \\
0.01\end{array}$ & $\begin{array}{c}0.001 \\
0.92 \\
0.001\end{array}$ & $\begin{array}{l}(44.5 \%) \\
(50.0 \%) \\
(39.6 \%)\end{array}$ \\
\hline $\begin{array}{l}\text { Model } 3 \\
\quad \text { Intercept }\end{array}$ & -1.37 & 0.02 & 0.001 & $(20.2 \%)$ \\
\hline $\begin{array}{l}\text { Race/ethnicity } \\
\text { White } \\
\text { Black } \\
\text { Hispanic }\end{array}$ & $\begin{array}{c}\text { Reference } \\
0.20 \\
-0.17\end{array}$ & $\begin{array}{l}0.01 \\
0.01\end{array}$ & $\begin{array}{l}0.001 \\
0.001\end{array}$ & $\begin{array}{l}1.22 \\
0.84\end{array}$ \\
\hline $\begin{array}{l}\text { Gender } \\
\text { Female } \\
\text { Male }\end{array}$ & $\begin{array}{c}\text { Reference } \\
0.38\end{array}$ & 0.01 & 0.001 & 1.46 \\
\hline $\begin{array}{l}\text { Age at placement } \\
\text { Spell age } 10 \\
\text { Spell age } 11 \\
\text { Spell age } 12-13 \\
\text { Spell age } 14-15 \\
\text { Spell age } 16-17\end{array}$ & $\begin{array}{c}\text { Reference } \\
0.25 \\
0.82 \\
1.38 \\
1.46\end{array}$ & $\begin{array}{l}0.02 \\
0.02 \\
0.02 \\
0.02\end{array}$ & $\begin{array}{l}0.001 \\
0.001 \\
0.001 \\
0.001\end{array}$ & $\begin{array}{l}1.29 \\
2.28 \\
3.97 \\
4.31\end{array}$ \\
\hline
\end{tabular}

Next, we turn our attention to contextual effects. We built a model with three intercepts, one for White youth, one for Black youth, and one for Hispanic youth. With this model structure, it is possible to see how the baseline congregate care placement rates vary by race/ethnicity while controlling for age and gender at the youth-level and for social, system, and policy context at the county-level. 
For each group, the baseline risk of congregate care placement is for White, Black, and Hispanic females who entered care at age 10 and were living in the least socially disadvantaged counties, urban core counties, and counties where there is no measurable supply effect on demand. In Model 2 of Table 4, the unadjusted likelihood of congregate care placement was 44.5 percent for White youth, 50.0 percent for Black youth, and 39.6 percent for Hispanic youth. According to Table 5, for 10-year old White females, the adjusted probability of entering congregate care was 14.4 percent, a figure that reflects the fact that females and younger children face lower utilization, as do children from urban core counties, counties where there is no detectable supply effect, and where social disadvantage is low. The comparable figures for Black and Hispanic youth are 17.0 and 14.1 percent.

More socially disadvantaged counties tend to have lower congregate care placement rates, although the statistical significance of the results depends on race/ethnicity. For Black and Hispanic youth, counties with low social disadvantage have higher congregate care placement rates than counties with higher levels of social disadvantage. Urban core counties also tend to place youth in congregate care at lower rates, but the effect size depends on race and ethnicity. Of the county-level characteristics, the supply effect has the strongest relationship to congregate care placement net of the other factors in the model. Moreover, although the supply effect is statistically significant for all three groups, the association is stronger for White youth $(0.59)$ than for Black youth (0.54) or Hispanic youth (0.47). Lastly, youth are less likely to be placed in congregate care in states that mandate the use of assessment than in states without such a mandate, as one would expect. ${ }^{1}$

\footnotetext{
${ }^{1}$ We take up the issue more fully in the limitation section of the paper, but it is worth mentioning here that policy effects are hard to interpret because of endogeneity: Is utilization lower because of the policy or do states with low utilization tend to pass
} 
Table 5 shows the parameter estimates from a two-level mixed effects model with youth nested with counties. Mixed effects models offer a number of advantages including an adjustment for unit size. Children within the same counties and states are more similar to each other than children in other counties and states. Without considering the correlations within counties and states, each child provides the same amount of information regardless of the size of counties and states. In logistic regression models that ignore the nested structure of the data, large counties or states (as in this case) contribute far more information to the model than small counties and states do. For example, in studies of foster care that means that the national average estimate is, without adjustment, more about large states like California than about small states like New Hampshire.

Unlike the results in Tables 3 and 4, which do not account for either state or county clustering, the results in Table 5 take county clustering into account. The results in Table 6, which are based on a three-level mixed effects model, account for both county and state clustering. That said, the adjustment for county and state clustering does not, per se, alter the basic narrative. Age and gender are still positively correlated with the likelihood of congregate care placement, with 16 and 17 year olds having especially high congregate care placement rates. With respect to context, the narrative is also unchanged: congregate care placement is less likely in urban core counties and in counties with more social disadvantage. However, the significance of the differences tends to shift toward less significant, in a statistical sense, because state differences explain part of the between county differences. The supply effect on demand is the one factor that remains statistically significant as one moves between one, two, and three level 
models. In each case, the likelihood of congregate care placement is substantially higher in counties where a relationship between demand and supply was detected. 
Table 5: Likelihood of Congregate Care Placement by Child and County Characteristics:

Logistic Regression with County Random Effect

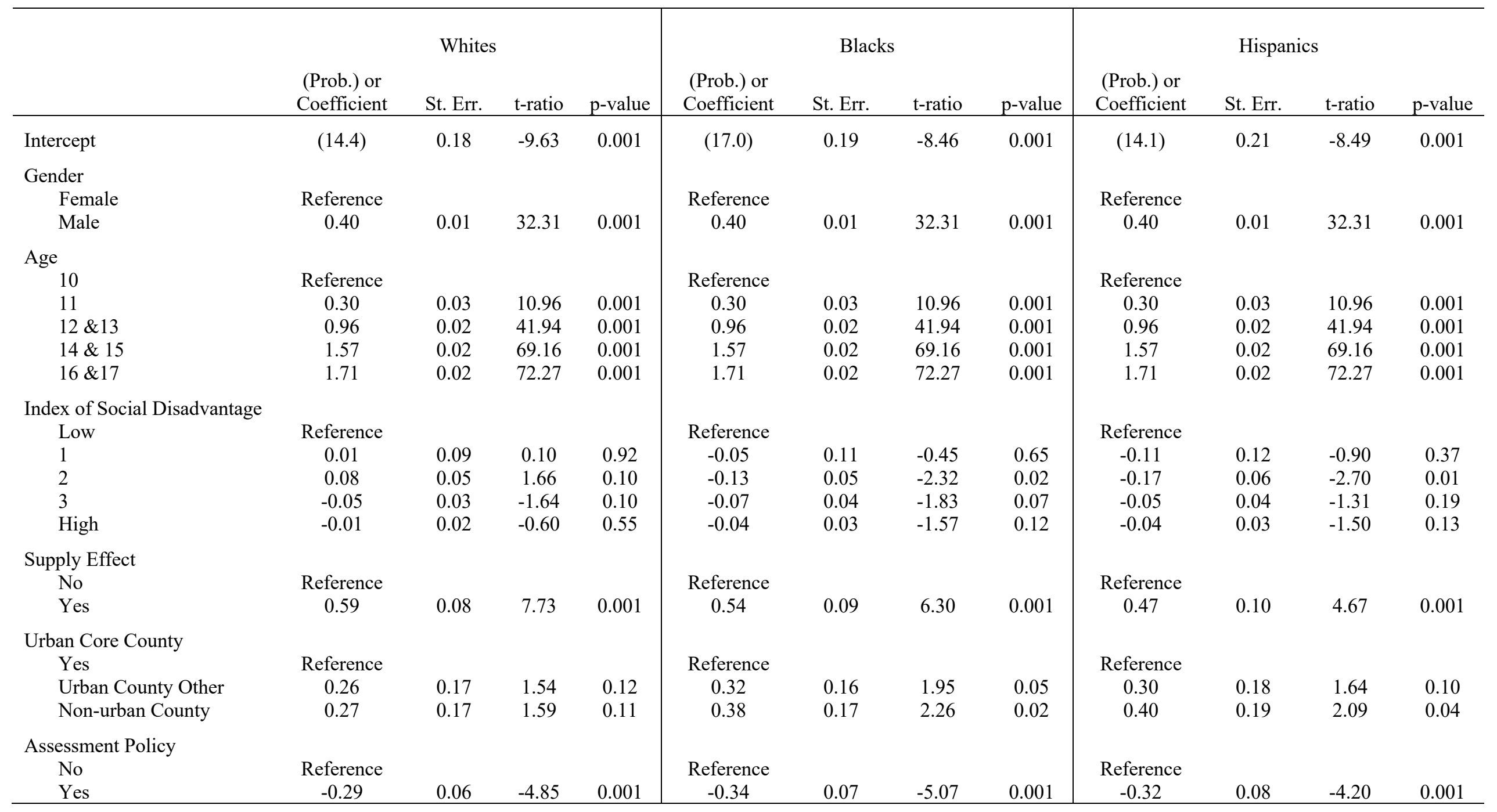


Table 6: Likelihood of Congregate Care Placement by Child and County Characteristics: Logistic Regression with County and State Random Effects

\begin{tabular}{|c|c|c|c|c|c|c|c|c|c|c|c|c|}
\hline & \multicolumn{4}{|c|}{ Whites } & \multicolumn{4}{|c|}{ Blacks } & \multicolumn{4}{|c|}{ Hispanics } \\
\hline & $\begin{array}{c}\text { (Prob.) or } \\
\text { Coefficient }\end{array}$ & $\begin{array}{l}\text { St. } \\
\text { Err. }\end{array}$ & t-ratio & $\begin{array}{c}\mathrm{p}- \\
\text { value }\end{array}$ & $\begin{array}{c}\text { (Prob.) or } \\
\text { Coefficient }\end{array}$ & St. Err. & t-ratio & $\begin{array}{c}\mathrm{p}- \\
\text { value }\end{array}$ & $\begin{array}{c}\text { (Prob.) or } \\
\text { Coefficient }\end{array}$ & St. Err. & t-ratio & $\begin{array}{c}\mathrm{p}- \\
\text { value }\end{array}$ \\
\hline Intercept & (14.4) & 0.22 & -8.28 & 0.001 & (16.5) & 0.00 & 0.00 & 0.00 & (14.2) & 0.24 & -7.47 & 0.001 \\
\hline $\begin{array}{l}\text { Gender } \\
\text { Female } \\
\text { Male }\end{array}$ & $\begin{array}{c}\text { Reference } \\
0.44\end{array}$ & 0.02 & 24.38 & 0.001 & $\begin{array}{c}\text { Reference } \\
0.44\end{array}$ & 0.02 & 24.38 & 0.001 & $\begin{array}{c}\text { Reference } \\
0.44\end{array}$ & 0.02 & 24.38 & 0.001 \\
\hline $\begin{array}{l}\text { Age } \\
\qquad \begin{array}{l}10 \\
11 \\
12 \& 13 \\
14 \& 15 \\
16 \& 17\end{array}\end{array}$ & $\begin{array}{l}\text { Reference } \\
0.30 \\
0.96 \\
1.57 \\
1.71\end{array}$ & $\begin{array}{l}0.03 \\
0.02 \\
0.02 \\
0.02\end{array}$ & $\begin{array}{l}10.93 \\
41.92 \\
69.19 \\
72.42\end{array}$ & $\begin{array}{l}0.001 \\
0.001 \\
0.001 \\
0.001\end{array}$ & $\begin{array}{c}\text { Reference } \\
0.30 \\
0.96 \\
1.57 \\
1.71\end{array}$ & $\begin{array}{l}0.03 \\
0.02 \\
0.02 \\
0.02\end{array}$ & $\begin{array}{l}10.93 \\
41.92 \\
69.19 \\
72.42\end{array}$ & $\begin{array}{l}0.001 \\
0.001 \\
0.001 \\
0.001\end{array}$ & $\begin{array}{c}\text { Reference } \\
0.30 \\
0.96 \\
1.57 \\
1.71\end{array}$ & $\begin{array}{l}0.03 \\
0.02 \\
0.02 \\
0.02\end{array}$ & $\begin{array}{l}10.93 \\
41.92 \\
69.19 \\
72.42\end{array}$ & $\begin{array}{l}0.001 \\
0.001 \\
0.001 \\
0.001\end{array}$ \\
\hline $\begin{array}{l}\text { Index of Social } \\
\text { Disadvantage } \\
\text { Low } \\
1 \\
2 \\
3 \\
\text { High }\end{array}$ & $\begin{array}{l}\text { Reference } \\
-0.01 \\
-0.07 \\
-0.02 \\
-0.03\end{array}$ & $\begin{array}{l}0.08 \\
0.04 \\
0.03 \\
0.02\end{array}$ & $\begin{array}{l}-0.13 \\
-1.67 \\
-0.68 \\
-1.38\end{array}$ & $\begin{array}{l}0.90 \\
0.10 \\
0.50 \\
0.17\end{array}$ & $\begin{array}{l}\text { Reference } \\
-0.07 \\
-0.11 \\
-0.04 \\
-0.05\end{array}$ & $\begin{array}{l}0.10 \\
0.05 \\
0.03 \\
0.02\end{array}$ & $\begin{array}{l}-0.73 \\
-2.23 \\
-1.27 \\
-2.11\end{array}$ & $\begin{array}{l}0.47 \\
0.03 \\
0.21 \\
0.04\end{array}$ & $\begin{array}{c}\text { Reference } \\
-0.16 \\
-0.16 \\
-0.03 \\
-0.06\end{array}$ & $\begin{array}{l}0.11 \\
0.06 \\
0.04 \\
0.03\end{array}$ & $\begin{array}{l}-1.48 \\
-2.90 \\
-0.71 \\
-2.37\end{array}$ & $\begin{array}{l}0.14 \\
0.00 \\
0.48 \\
0.02\end{array}$ \\
\hline $\begin{array}{l}\text { Supply Effect } \\
\text { No } \\
\text { Yes }\end{array}$ & $\begin{array}{l}\text { Reference } \\
0.58\end{array}$ & 0.07 & 8.86 & 0.001 & $\begin{array}{l}\text { Reference } \\
0.55\end{array}$ & 0.08 & 6.95 & 0.001 & $\begin{array}{c}\text { Reference } \\
0.49\end{array}$ & 0.09 & 5.38 & 0.001 \\
\hline $\begin{array}{l}\text { Urban Core County } \\
\text { Yes } \\
\text { Urban County - Other } \\
\text { Non-urban County }\end{array}$ & $\begin{array}{c}\text { Reference } \\
0.13 \\
0.12\end{array}$ & $\begin{array}{l}0.13 \\
0.13\end{array}$ & $\begin{array}{l}0.98 \\
0.89\end{array}$ & $\begin{array}{l}0.33 \\
0.38\end{array}$ & $\begin{array}{c}\text { Reference } \\
0.24 \\
-0.29\end{array}$ & $\begin{array}{l}0.15 \\
0.22\end{array}$ & $\begin{array}{c}1.65 \\
-1.29\end{array}$ & $\begin{array}{l}0.10 \\
0.20\end{array}$ & $\begin{array}{c}\text { Reference } \\
0.17 \\
0.23\end{array}$ & $\begin{array}{l}0.15 \\
0.16\end{array}$ & $\begin{array}{l}1.17 \\
1.41\end{array}$ & $\begin{array}{l}0.24 \\
0.16\end{array}$ \\
\hline $\begin{array}{l}\text { Assessment Policy } \\
\text { No } \\
\text { Yes }\end{array}$ & $\begin{array}{l}\text { Reference } \\
\quad-0.22 \\
\end{array}$ & 0.25 & -0.90 & 0.37 & $\begin{array}{c}\text { Reference } \\
-0.29 \\
\end{array}$ & 0.22 & -1.29 & 0.20 & $\begin{array}{c}\text { Reference } \\
-0.31\end{array}$ & 0.26 & -1.23 & 0.22 \\
\hline
\end{tabular}




\section{Disparity}

To measure disparity directly, we use our model results to compute the Black/White and Hispanic/White odds ratios given the characteristics of the youth and the county where they were living at the time they entered care. Consider, for example, the counties in which no supply effect on demand was detected and in which the use of an assessment to regulate congregate care placements is not mandated by the state. Given those (ecological) similarities, we examine how the racial and ethnic disparities in congregate care placement in those counties compare with the level of disparity in counties with a different profile.

The final results of our analysis are presented in Table 7. The three intercepts represent the likelihood that a Black or White or Hispanic youth (female age 10) will be placed in congregate care. The likelihood is raised or lowered based on the whether the county where the youth was living is one where a supply signal was detected and/or an assessment was mandated. Each coefficient (i.e., the logit from the logistic regression model) is summed to derive a total, depending on the combination of a race/ethnicity, a supply signal and an assessment policy. The total is then exponentiated (exp (total coefficient)) to produce the odds. The ratio of the odds is based on this result. For convenience, we also show the probability, which represents the likelihood a youth in a county with a particular combination of characteristics will be placed in congregate care. The probability is calculated as: (odds / $(1+$ odds $))$.

Three sets of results are presented in Table 7. The first panel shows the results from the logistic regression model that does not account for county or state clustering. Although only the parameter estimates for county characteristics are displayed, age and gender are included in the underlying statistical models. In the probability calculations, baseline age (10) and gender 
(female) are used. Those parameter estimates are not shown because the ratio of the odds is not dependent on gender or age.

Table 7: Congregate Care Placement Rates for Black, White, and Hispanic Children with Odds Ratios

\begin{tabular}{|c|c|c|c|c|c|c|c|c|c|}
\hline \multirow[b]{2}{*}{$\begin{array}{l}\text { Race/ } \\
\text { Ethnicity }\end{array}$} & \multicolumn{2}{|c|}{ County Context } & \multicolumn{4}{|c|}{ Logits } & \multirow[b]{2}{*}{ Odds } & \multirow[b]{2}{*}{ Probability } & \multirow[b]{2}{*}{ Disparity } \\
\hline & Signal & $\begin{array}{c}\text { Assess. } \\
\text { Policy }\end{array}$ & Intercept & Signal & $\begin{array}{l}\text { Assess. } \\
\text { Policy }\end{array}$ & Total & & & \\
\hline \multicolumn{10}{|c|}{ Fixed effect model } \\
\hline White & No & No & -1.48 & & & -1.48 & 0.23 & 0.19 & \\
\hline White & Yes & No & -1.48 & 0.45 & & -1.03 & 0.36 & 0.26 & \\
\hline White & No & Yes & -1.48 & & -0.39 & -1.88 & 0.15 & 0.13 & \\
\hline White & Yes & Yes & -1.48 & 0.45 & -0.39 & -1.43 & 0.24 & 0.19 & \\
\hline Black & No & No & -1.12 & & & -1.12 & 0.33 & 0.25 & 1.43 \\
\hline Black & Yes & No & -1.12 & 0.17 & & -0.96 & 0.38 & 0.28 & 1.08 \\
\hline Black & No & Yes & -1.12 & & -0.51 & -1.63 & 0.19 & 0.16 & 1.27 \\
\hline Black & Yes & Yes & -1.12 & 0.17 & -0.51 & -1.47 & 0.23 & 0.19 & 0.96 \\
\hline Hispanic & No & No & -1.85 & & & -1.85 & 0.16 & 0.14 & 0.69 \\
\hline Hispanic & Yes & No & -1.85 & 0.23 & & -1.62 & 0.20 & 0.17 & 0.56 \\
\hline Hispanic & No & Yes & -1.85 & & 0.31 & -1.54 & 0.21 & 0.18 & 1.40 \\
\hline Hispanic & Yes & Yes & -1.85 & 0.23 & 0.31 & -1.31 & 0.27 & 0.21 & 1.13 \\
\hline \multicolumn{10}{|c|}{ County random intercept } \\
\hline White & No & No & -1.59 & & & -1.59 & 0.20 & 0.17 & \\
\hline White & Yes & No & -1.59 & 0.57 & & -1.02 & 0.36 & 0.26 & \\
\hline White & No & Yes & -1.59 & & -0.29 & -1.88 & 0.15 & 0.13 & \\
\hline White & Yes & Yes & -1.59 & 0.57 & -0.29 & -1.31 & 0.27 & 0.21 & \\
\hline Black & No & No & -1.37 & & & -1.37 & 0.26 & 0.20 & 1.25 \\
\hline Black & Yes & No & -1.37 & 0.48 & & -0.88 & 0.41 & 0.29 & 1.15 \\
\hline Black & No & Yes & -1.37 & & -0.34 & -1.71 & 0.18 & 0.15 & 1.19 \\
\hline Black & Yes & Yes & -1.37 & 0.48 & -0.34 & -1.23 & 0.29 & 0.23 & 1.09 \\
\hline Hispanic & No & No & -1.58 & & & -1.58 & 0.21 & 0.17 & 1.01 \\
\hline Hispanic & Yes & No & -1.58 & 0.40 & & -1.18 & 0.31 & 0.23 & 0.85 \\
\hline Hispanic & No & Yes & -1.58 & & -0.34 & -1.92 & 0.15 & 0.13 & 0.96 \\
\hline Hispanic & Yes & Yes & -1.58 & 0.40 & -0.34 & -1.52 & 0.22 & 0.18 & 0.81 \\
\hline \multicolumn{10}{|c|}{ State and county random intercepts } \\
\hline White & No & No & -1.71 & & & -1.71 & 0.18 & 0.15 & \\
\hline White & Yes & No & -1.71 & 0.61 & & -1.10 & 0.33 & 0.25 & \\
\hline White & No & Yes & -1.71 & & -0.24 & -1.95 & 0.14 & 0.12 & \\
\hline White & Yes & Yes & -1.71 & 0.61 & -0.24 & -1.34 & 0.26 & 0.21 & \\
\hline Black & No & No & -1.52 & & & -1.52 & 0.22 & 0.18 & 1.22 \\
\hline Black & Yes & No & -1.52 & 0.56 & & -0.96 & 0.38 & 0.28 & 1.16 \\
\hline Black & No & Yes & -1.52 & & -0.31 & -1.82 & 0.16 & 0.14 & 1.13 \\
\hline Black & Yes & Yes & -1.52 & 0.56 & -0.31 & -1.26 & 0.28 & 0.22 & 1.08 \\
\hline Hispanic & No & No & -1.74 & & & -1.74 & 0.18 & 0.15 & 0.80 \\
\hline Hispanic & Yes & No & -1.74 & 0.49 & & -1.25 & 0.29 & 0.22 & 0.75 \\
\hline Hispanic & No & Yes & -1.74 & & -0.34 & -2.08 & 0.13 & 0.11 & 0.78 \\
\hline Hispanic & Yes & Yes & -1.74 & 0.49 & -0.34 & -1.59 & 0.20 & 0.17 & 0.72 \\
\hline
\end{tabular}


If we regard counties with no supply signal and no assessment mandate as the baseline case, then the disparity level in those counties is higher than in any other counties. The ratio of the underlying Black/White odds is $1.43(=0.33 / 0.23)$. The Hispanic/White odds ratio is .69 $(=0.16 / 0.23)$. If we shift our attention to counties where a supply signal is detected, the probability of congregate care placement jumps to 26 percent for White female 10 -year-olds, to 28 percent for Black female 10-year-olds and to 17 percent for Hispanic female 10-year-olds. As a consequence, the odds ratios shift to $1.08(=0.38 / 0.36)$ and $0.56(=0.16 / 0.36)$, respectively.

In counties without a detectable supply signal present but with an assessment mandate, the disparity ratio also narrows relative to the baseline (i.e., counties where there is no signal and there is no assessment mandate). Generally, whether a 10 -year old female is placed in congregate care, depends on the county context.

The two other panels in Table 7 provide identical information when the models account for county random effects (the second panel) and county and state random effects (the third panel). Although the point estimates differ, the narrative is essentially the same. The estimated level of disparity depends on the combination of county characteristics. If there is no supply signal driving congregate care placement rates higher and no mandatory assessment tending to push congregate care placement rates lower, Black/White differences grow and White/Hispanic differences shrink. By themselves, the supply signal and the assessment mandate are associated with lower levels of disparity but the lowest levels of disparity are found in counties with both a supply effect and a mandatory assessment.

It is, however, important to note the underlying mechanics behind this outcome. Looking at the parameter estimates in Table 7 (under the columns labeled Logits), invariably the supply effect is stronger for White youth than for either Black youth or Hispanic youth. For instance, in 
the second panel (county random effect), the supply logit is 0.57 for White youth, 0.48 for Black youth and 0.40 for Hispanic youth. Assessment policy also has a differential impact. In both the second and third panels, the logit for White youth is larger than the logit for Black and Hispanic youth.

The association between a mandatory assessment policy and congregate care placement is in the expected direction. Counties in states that mandate an assessment have the lowest congregate care placement rates. Mandatory assessment policies are also associated with lower levels of disparity because of a differential effect on White youth. Finally, congregate care placement rates are lower in counties with the combination of a supply effect and a mandatory assessment policy than in counties where only the supply effect is present and higher in counties where only the mandatory assessment policy is in place.

\section{Limitations and Implications}

Before considering the implications of our results, we want to bring forward the limitations of our study. First, there is the question of how we measured congregate care utilization. Youth can be placed in congregate care at any point during a foster care spell. Here we looked at congregate care placements without regard to whether they were a first placement or a step up from family-based care. Our results might have been different had we considered the timing of congregate care placements or length of stay in congregate care, another important measure of utilization. Be that as it may, changes in parameter estimates in this context are not per se problematic. If parameter estimates change with changes in our measure of utilization, it would be important to ask where the results differ and why. Are there other features of the system at work and what do those features tell us about the role of context as a factor tied to Black/White and Hispanic/White disparities? In other words, the findings presented here create a backdrop for 
further, theoretically motivated explorations. For example, among other system factors, the use of shelters is a potential driver of what we find because children are often placed in shelters while child welfare workers make efforts to find an appropriate placement. It is important feature of some local systems but the use of shelters may simply demonstrate the built-bed-is-a-filledbed prophecy. That states and localities often manage the use of shelters by closing them down merely substantiates the point. If you don't want to fill the shelter beds, close the shelters. Otherwise, there is tendency to use the beds.

It should also be noted that our models did not include some of the child-level covariates that probably influence whether young people are placed in congregate care. Congregate care is generally used to address the behavioral health needs of young people so the absence of behavioral health indicators in our models is a weakness. We also acknowledge that the child welfare system is but one system used to deal with young people exhibiting behavioral health needs. Adolescents, a focus of this study, are often involved in the juvenile justice system as opposed to the child welfare system, and state policies regarding the connection between juvenile justice and child welfare vary considerably. There is clearly more to learn about if and how the two systems work together, particularly given that Black youth are also over-represented in the juvenile justice system.

Our county-level measures of social disadvantage and the supply effect on demand are probably too crude to articulate a more nuanced understanding of how county context influences congregate care utilization. On the one hand, studies of ecological similarity often target areas at smaller spatial scales so one has to consider whether county as the unit of analysis masks important relationships viewed only at smaller spatial scales (e.g., neighborhoods). On the other hand, because family courts are often organized at the county-level and judges have considerable 
sway in placement orders, ignoring county as the unit of analysis may impose its own empirical cost (Halloran, 2018). There is as well a body of literature that suggests spatial scale is less important than one might think (Lery, 2009). In the end, the issue of spatial scale and its import within the body of ecological analysis is an empirical question that is well worth exploring.

For social disadvantage, the five-point scale ( 0 to 4$)$ is based on state-centered means. A more sophisticated approach might cluster counties into a larger number of more homogeneous ecological groupings. What we have done here, however, is establish the possibility that such nuances are important and should be studied. The same can be said for our measure of bed supply in relation to placement. We distinguished between counties where we detected a signal and counties where we did not. The underlying data are, however, continuous in form. Use of a continuous variable might reveal other equally important patterns. We also acknowledge that we defined county context in terms of one ecological construct, one system construct, and one policy construct when county context may be more complicated. For instance, states vary widely in the policy framework used to manage congregate care, and the assessment mandate may be tied to a latent construct that more thoroughly describes how states differ from a policy perspective. These are not limitations as much as they are avenues for future research.

Lastly, as mentioned earlier, we are only able to describe the correlation between a policy that requires the use of an assessment and the use of congregate care. We know little about the actual implementation of those policies. Nevertheless, the federal government has recently passed a law that requires the use of an assessment as a condition of placement into qualified residential treatment programs (QRTPs). Hence, it will soon be possible to study the effects of assessment on the use of congregate care under the conditions of a natural experiment. What our study tells us is that counties in states with policies that mandate assessments use less congregate 
care than states without such policies. What our study also suggests is that the magnitude of that effect interacts with the supply signal when that signal is also present. Whether the supply effect moderates the benefits of assessment or the benefits of assessment are undercut by supply effects is an important questions for policy and practice, especially because both seem connected to the observed disparity in congregate care placement rates.

The latter observations return the discussion to the larger purpose of the paper. We did not set out to put the question of disparity in congregate care placement rates and the role of context in those disparities to rest. On the contrary, we hope to open that line of inquiry by showing that disparity in congregate care placement rates does in fact vary in rough alignment with theoretically important constructs. In particular, although we tend to believe that decisions to place youth in congregate care are based on the merits of the individual case (hence the assessment mandates), we also understand that child welfare workers are constrained in the choices they can make (Emerson, 1982; Leibovitch, 2015). Supply-induced demand represents one such constraint operating within the child welfare worker's context that frames the relative nature of decision-making. Another is the time child welfare workers have to spend gathering the information needed to make informed decisions (Edwards \& Wildeman, 2018). We think it is important to understand if and how these constraints influence what happens to young people and if there is a link between those constraints and the disparities in congregate care placement rates between Black, Hispanic, and White youth. If these constraints are systemic in nature then the range of policy and practice options under consideration should be reviewed.

We set out, in this paper, to show that the magnitude of disparities in the use of congregate care shift when youth in ecologically similar contexts are grouped together. We were particularly interested in the supply effect on demand as a way to think about ecological context. In prior 
studies, context in child welfare research is still largely defined in terms of aspects of social ecology including poverty and family structure. Although we too rely on such social ecological distinctions, we expand the notion of context by including attributes of the child welfare system. In counties where the supply effect on demand is strong, the congregate care placement rate is much higher than in counties where the supply effect on demand is weak or nonexistent. In practical terms, this means that congregate care placement is part of a system dynamic (Forrester, 1971) that ties utilization to supply. In our sample, seventy percent of White youth enter foster care in counties where no supply signal could be detected. However, our results suggest that in counties where a supply signal exists, the likelihood that a White youth will be placed in congregate care is 40 percent higher than in counties where it does not. This brings the congregate care placement rate for White youth rate much closer to rates for Black youth in similar counties. Congregate care placement rates for Black and Hispanic youth are also higher in counties where there is a supply effect but the shift in congregate care utilization is not as dramatic. This is the difference that underlies the change in the Black/White and Hispanic/White disparities. Theory predicts that the experiences of White youth will be more similar to the experiences of Black youth if the White youth reside in places that look like the places where Black youth reside. If, upon closer scrutiny, these findings hold up, we have added to a body of research that says residential segregation sustains the Black/White gap in so much of American life.

The focus on Black youth as compared to White youth risks drawing our attention away from the experiences of Hispanic youth. As others have found, the Hispanic/White disparity is different from the Black/White disparity in maltreatment rates (Maguire-Jack et al., 2015). Essentially, Hispanic youth are less likely to be placed in congregate care than White youth, 
although the effect of context is basically the same. Congregate care placement rates are highest for Hispanic youth in counties where there is a supply effect and no assessment is required and lowest in counties where there is no supply effect and assessment is mandated, just as it is with Black and White youth. However, the dynamics of context cause Hispanic/White disparity to widen because the baseline disparity reflects lower overall utilization of congregate care. That is, Hispanic youth are even less likely to be placed in congregate care than White youth. Although theory predicts that the level of disparity will be sensitive to context, we do not yet know why. Again, the goal here has been to demonstrate how attention to context introduces a potentially important line of research. If that research undercuts the theory of ecological similarity then we will have learned something even more important about disparity and its causes.

From a policy perspective, our finding that supply effects are implicated in the Black/White and Hispanic/White differences means that policy solutions that address bed supply more explicitly are needed. Unfortunately, to our knowledge, few if any states are actively engaged in planning around bed supply in a rigorous fashion. Instead, states tend to prefer strategies that strengthen screening mechanisms as a way to control access to congregate care. Provisions of the Family First Prevention Services Act of 2018 pertaining to congregate utilization reflect this tendency. For example, Section 50742 of the Act ties federal reimbursement to assessment and documentation of the need for placement in a Qualified Residential Treatment Program (Family First, 2018). However, if supply affects utilization, screening mechanisms will be more effective if the supply effects have been mitigated by aligning the supply of beds with expectations regarding the level of need for congregate care measured not at the individual-level but at the population-level. 


\section{References}

Coulton, C. J., Korbin, J. E., Su, M., \& Chow, J. (1995). Community Level Factors and Child Maltreatment Rates. Child Development, 66, 1262-1276.

Dozier, M., Kaufman, J., Kobak, R., O'Connor, T. G., Sagi-Schwartz, A., Scott, S., Shauffer, C., Smetana, J., van IJzendoorn, M.H., Zeanah, C.H. (2014). Consensus statement on group care for children and adolescents: A statement of policy of the American Orthopsychiatric Association. American Journal of Orthopsychiatry, 84, 219-225.

Edwards, F., \& Wildeman, C. (2018). Characteristics of the Front-Line Child Welfare Workforce. Children and Youth Services Review, 89, 1-15.

Emerson, R. (1982). Holistic effects in social control decision-making. Law \& Society Review, 17, 425-456.

Family First Prevention Services Act. Family First Prevention Services Act (2018). 42 USC Chapter 67.

Fluke, J., Jones, B., Jenkins, M., \& Ruehrdanz, A. (2011). Research Synthesis on Child Welfare: Disproportionality and Disparities. Washington, DC: Center for the Study of Social Policy/Annie E. Casey Foundation.

Forrester, J. W. (1971). Counterintuitive behavior of social systems. Theory and Decision, 2, 109-140.

Halloran, J. (2018). Population dynamics in the child welfare system (Doctoral dissertation). Available from ProQuest Central; ProQuest Dissertations \& Theses Global. (ProQuest No. 10838784).

Ingram, D. D., \& Franco, S. J. (2014). 2013 NCHS Urban-Rural Classification Scheme for Counties. Vital Health Stat 2(166) (2nd ed.). Hyattsville, MD. 
Leibovitch, A. (2015). Relative Judgments. Available at SSRN 2622585.

Lery, B. (2009). Neighborhood structure and foster care entry risk: The role of spatial scale in defining neighborhoods. Children and Youth Services Review, 31, 331-337.

Maguire-Jack, K., Lanier, P., Johnson-Motoyama, M., Welch, H., \& Dineen, M. (2015).

Geographic variation in racial disparities in child maltreatment: The influence of county poverty and population density. Child Abuse \& Neglect, 47, 1-13.

Roemer, M. (1961). Bed Supply and Hospital Utilization: A Natural Experiment. Hospitals, 35, $36-42$.

Sampson, R., \& Bean, L. (2006). Cultural Mechanisms and Killing Fields: A Revised Theory of Community Level Racial Inequality. The Many Colors of Crime: Inequalities of Race.

Sugihara, G., May, R., Ye, H., Hsieh, C.-H., Deyle, E., Fogarty, M., \& Munch, S. (2012).

Detecting causality in complex ecosystems. Science, 338, 496-500.

Wulczyn, F. H., Daro, D., Fluke, J., Feldman, S., Glodek, C., \& Lifanda, K. (2010). Adapting a Systems Approach to Child Protection. UNICEF.

Wulczyn, F., \& Halloran, J. (2017). Foster Care Dynamics and System Science: Implications for Research and Policy. International Journal of Environmental Research and Public Health, 14, 1181-12.

Wulczyn, F., Alpert, L., Martinez, Z., \& Weiss, A. (2015). Within and Between State Variation in the Use of Congregate Care (pp. 1-18). Chicago: Chapin Hall Center for Children, University of Chicago.

Wulczyn, F., Gibbons, R., Snowden, L., \& Lery, B. (2013). Poverty, Social Disadvantage, and the Black/White Placement Gap. Children and Youth Services Review, 35, 65-74. 